\title{
Results of the Bell Chemistry Test
}

\author{
Thomas H. Briggs \\ Teachers College, Columbia University.
}

T ATE in March, I920, the Bell Chemistry Test ${ }^{1}$ was given to 27 pupils in the Reading, Pennsylvania, Boys' High School, and to II pupils in the Horace Mann High School for Boys, of Teachers' College, Columbia University. As an addition to Bell's tentative standards, the results are here reported in Table $\mathrm{I}$.

TABLE I.

Showing the Scores in Bell Chemistry Test for 38 Boys, March, 1920.

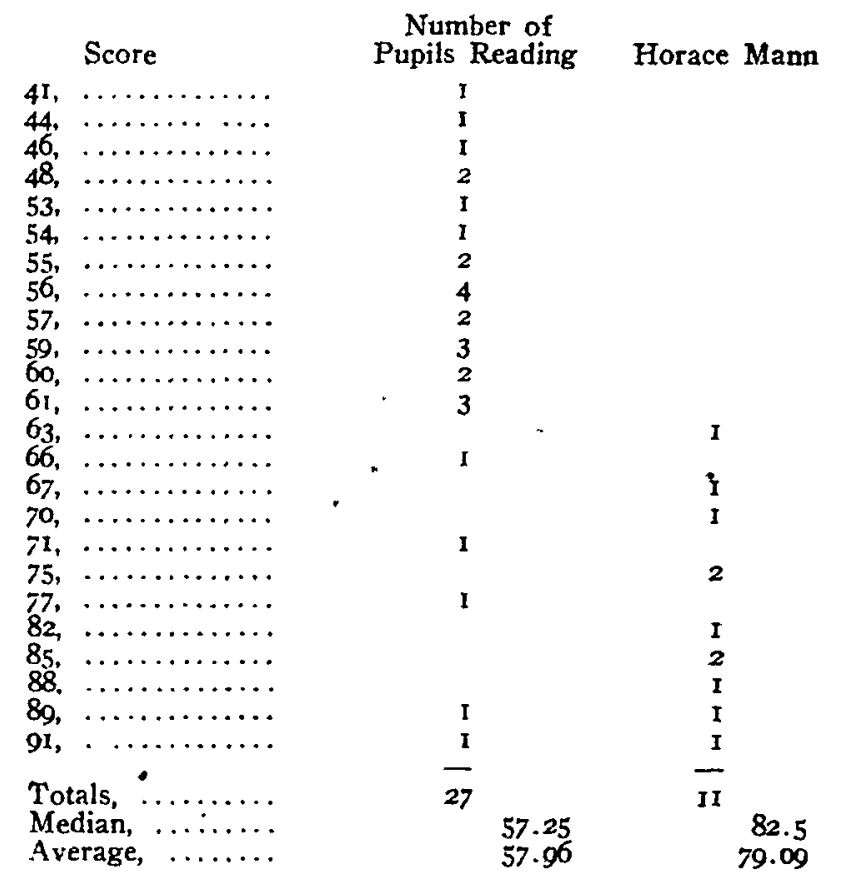

Although the pupils tested had studied chemistry for only a little over six months, their scores compare favorably with those of the Texas pupils who had pursued the subject for eight months. This

7. Jonrnal of Edacational Psychology, Vol. 9, 1918, 189. 
suggests that Bell's tentative scores may be low. The list should be applied to a number of other pupils in different states.

In order to secure some measure of reliability of the test, correlations were made between the scores, the marks of the pupils in chemistry for the first semester, and the estimates by the teachers of the pupils' knowledge of chemistry at the time the list was given. The correlations between the last two items are of course spurious, as the ranks come from the same source; but they serve to indicate something of the unreliability of teachers' judgments. The results are shown in Table II, the P. E.'s being given in parenthesis. As not all of the pupils considered received three marks, the numbers involved vary slightly.

TABLE II.

Showing the coefficients or correlation $\left[\rho=1-\frac{6 \Sigma \mathrm{d}^{2}}{n\left(n^{2}-1\right)}\right]$ between scores in the

Bell Chemistry Test, Semester Marks, and Teachers' Estimates of the Pupils' Knowledge of the Subject.

\begin{tabular}{|c|c|c|c|c|}
\hline Marks & $\begin{array}{l}\text { Teachers' } \\
\text { Estimates }\end{array}$ & & Marks & $\begin{array}{l}\text { Teachers' } \\
\text { Estimates }\end{array}$ \\
\hline 300 (P.E. .214) & $\begin{array}{l}.388 \text { (P.E. .197) } \\
.557 \text { (P.E. .12I) }\end{array}$ & $\begin{array}{l}\text { Test } \\
\text { Marks }\end{array}$ & .414 (P.E. .117) & $\begin{array}{ll}.352 & \text { (P.E. . } .26) \\
.871 & \text { (P.E. . .029) }\end{array}$ \\
\hline
\end{tabular}

These raw coefficients may be interpreted as showing that the test is a fairly good measure of a class knowledge of chemistry; but a study of the detailed pairings indicate that it is unreliable for an individual. Satisfactory high relationship between the results of the test and teachers' marks can not be expected when the coefficient between a teacher's marks and estimates runs as low as .56 .

As in the original article Bell did not give a scoring sheet and as that used in Texas has been lost, one prepared by Mr. Robert F. Payne is appended for the convenience of others desiring to use the test.

\section{Beli Chemistry Test}

I. What chemicals are liberated in the electrolysis of water?

2. What gas is given off by the action of yeast in bread dough?

3. Name two chemicals used in making oxygen.

4. Express in cubic centimeters, one liter.

5. Name two substances used in making hydrogen.

6. Define oxidation. 
7. Define reduction.

8. Name four processes of purifying water.

9. What is a deliquescent substance?

Io. Name two gases either of which might be used to bleach cloth or flowers.

1I. Name two very common organic acids.

12. Name two chemical compounds used in making common salt.

13. Write the reaction for sulphuric acid on potassium hydroxide.

I4. Name the two most abundant elements in the atmosphere.

I5. Name two commercial sources of ammonia.

I6. Is air a chemical or a physical mixture?

17. Why does ammonia water always feel cold when it comes in contact with the hands?

18. Name the substances used to make aqua regia.

19. Name four basic hydroxides.

20. Name the commercial uses of the nitrates.

21. What are the properties of carbon bisulphide?

22. Give the chemical name of: $\mathrm{CaSO}_{4}$

$\mathrm{H}_{2} \mathrm{~S} . \ldots \ldots \ldots \ldots \ldots \mathrm{Na}_{2} \mathrm{SO}_{3} \ldots \ldots \ldots \ldots \ldots$

23. What is the calence of: $\mathrm{H} \ldots \ldots, \mathrm{O} \ldots, \mathrm{Ca}, \ldots, \mathrm{SO}_{4} \ldots$.

24. Name the members of the Chlorine group.

25. How many grams of water are formed by the combustion of ro grams of hydrogen in air?

Correction Shetex for Beli Chemistry Test

Allow 4 credits for each correct answer. I, 2, or 3 credits for partially correct answers. Avoid fractional credits by marking to the nearest full unit.

Possible

Credit Question

$\begin{array}{ll}4-2-0 & \text { I } \\ 4-0 & 2 \\ 4-2-0 & 3 \\ 4-0 & 4 \\ 4-0 & 5\end{array}$

Answer.

Hydrogen and oxygen. $\mathrm{H}_{2} \& \mathrm{O}_{2}, \mathrm{H} \& \mathrm{O}$.

Carbon dioxide. $\mathrm{CO}_{2}$

3 Potassium chlorate, Manganese dioxide, Mercury oxide, Barium oxide. (Any two.)

One thousand cubic centimeters. I000 cc.

5 Zine or Iron and Sulphuric acid. (Any common acid.) Sodium or Potassium and water. (Also accepted.) 
4-0

$4-0$

$4-3-2-1-0$

$+-2-0$

$4-3-2-0$

4-2-0

4-0

4-0

4-2-0

4-2-0

4-0

4-0

4-O

$4-3-2-1-0$

4-2-0

4-3-2-1-0

6 Oxidation is the combining of oxygen with an element or compound.

Oxidation means increase in valence. (Also accepted.)

7 Reduction is the taking away of oxygen from a compound.

Reduction means decrease in valence. (Also accepted.)

8 Filtration, boiling, freezing, distillation, sedimentation, chemical treatment. (Any four.)

9 A deliquescent substance is one that absorbs moisture from the air ( 2 point credit) to such an extent as to become liquid. (Full credit.)

Io Chlorine, Sulphur dioxide,-Nascent or atomic Oxygen. (For failure to specify nascent or atomic deduct one point credit.) (Any two.)

I I Acetic, tannic, citric, lactic, oxalic, etc. (Any two.)

12 Sodium hydroxide and Hydrochloric acid.

$132 \mathrm{KOH}+\mathrm{H}_{2} \mathrm{SO}_{4} \rightarrow \mathrm{K}_{2} \mathrm{SO}_{4}+2 \mathrm{HOH}$. (No deduction for failure to balance equation.) (Word equation accepted.)

I4 Nitrogen and Oxygen.

I5 From distillation of soft coal. Direct union of nitrogen and hydrogen by electricity.

I6 Physical.

I7 Because the rapid evaporation takes up heat.

I8 Nitric and Hydrochloric acids. (No credit unless both are correctly given.)

I9 Sodium hydroxide, Potassium hydroxide. Ammonium hydroxide, Calcium hydroxide, $\mathrm{Al}$ uminum hydroxide, etc. (Any four.)

20 Fertilizers and Explosives.

2 I Volatile liquid-strong odor-slight yellow in color-good solvent for many substancessomewhat inflammable. 
4-3-2-I $-22 \quad \mathrm{CaSO}_{4}$... Calcium Sulphate. $\mathrm{H}_{2} \mathrm{~S}$... Hydrogen sulphide. $\mathrm{Na}_{2} \mathrm{SO}_{3} \ldots$ Sodium sulphite.

4-3-2-I-O 23 Valence: H...One. O...Two. Ca...Two. $\mathrm{SO}_{4}$....Two.

4-3-2-x-0 24 Fluorine, Chlorine, Bromine, Iodine. (No deduction for failure to rename Chlorine.)

4-0 $25 \quad 90$ grams. 